\title{
PENGARUH VARIABEL SOSIAL EKONOMI, DEMOGRAFI DAN IPK TERHADAP FINANCIAL LITERACY \\ (Studi kasus terhadap mahasiswa Magister Manajemen di Universitas Udayana)
}

\author{
I Gusti Ngurah Narindra Mandala ${ }^{1}$ \\ Luh Putu Wiagustini ${ }^{2}$
}

\author{
${ }^{1,2}$ Fakultas Ekonomi dan Bisnis Universitas Udayana (Unud), Bali, Indonesia \\ e-mail: narindra.mandala@gmail.com
}

\begin{abstract}
ABSTRAK
Rendahnya tingkat financial literacy masyarakat, menjadikan sebuah kekhawatiran untuk menghadapi Masyarakat Ekonomi ASEAN (MEA). Penelitian ini akan meneliti faktor sosial ekonomi (masa bekerja dan tingkat pendapatan), faktor demografi (jenis kelamin dan status pernikahan), danfaktor IPK mahasiswa Program Studi Magister Manajemen Universitas Udayana. Data penelitian merupakan data primer yang diperoleh menggunakan instrumen penelitian berupa kuesioner, yang diisi langsung oleh mahasiswa yang bersangkutan baik secara langsungmaupun online. Teknik analisis yang digunakan adalah analisis PLS (Partial Least Square). Hasil penelitian menunjukkan bahwa faktor sosial ekonomi dan IPK berpengaruh secara positif dan signifikan terhadap financial literacy yang diukur berdasarkan indikator financial attitude, financial behavior dan financial knowledge. Temuan ini dapat memberikan kontribusi dalam bentuk empiris dan pengembangan refrensi Ilmu Manajemen Keuangan tentang pengaruh sosial ekonomi, demografi dan IPK terhadap financial literacy, serta untuk memudahkan lembaga keuangan menawarkan produk dan jasanya kepada mahasiswa Program Studi Magister Manajemen Unud.
\end{abstract}

Kata Kunci: Financial Literacy, Sosial Ekonomi, Demografi, Partial Least Square

\begin{abstract}
The low level of financial literacy amongst Indonesian people may concern to face ASEAN Economic Community (AEC). This study will analyze the sosio-economic factor(working period and income level), demographic factor (sex and marital status), and GPA factor of student of Master Management Program of Udayana University. The primary data is obtained using questionnaires, filled directly by the students concerned either directly or online. Analytical technique used in this study is partial least square analysis. The results shows that socioeconomic variable and GPA variable, are positively and significantly influence the financial literacy, measured by financial attitude, financial behavior and financial knowledge indicator. This findins are expected to contribute in the form of empirical and development of Financial Management Science refrence on socioeconomic, demographic and GPA influence the financial literacy, as well as to facilitate financial institutions when offering their products and services to Master of Management students at Unud.
\end{abstract}

Keywords: Financial Literacy, Socio-economic, Demographic, Partial Least Square 


\section{PENDAHULUAN}

Mengelola keuangan baik bagi perusahaan maupun individu merupakan salah satu kemampuan yang wajib ditingkatkan dalam hal mengatasi dampak persaingan global ini. Mien \& Thao (2015) mengungkapkan bahwa kegagalan dalam mengelola keuangan individu dapat menyebabkan permasalahan serius yang berkepanjangan, tidak hanya bagi individu tersebut namun akan berdampak pada perusahaannya. Perilaku manajemen keuangan individu telah mendapat perhatian para peneliti yang semakin meningkat dalam beberapa tahun terakhir. Menurutnya, manajemen keuangan individu didefinisikan sebagai sekumpulan perilaku mengenai perencanaan, pelaksanaan dan evaluasi yang terlibat dalam bidang perencanaan keuangan, kredit, investasi, asuransi, dana pensiun maupun rencana kepemilikan rumah.

Financial literacy merupakan salah satu cara agar terhindar dari masalah keuangan. Masyarakat termasuk mahasiswa perlu belajar untuk mengalokasikan dananya sedini mungkin dengan memahami konsep dari financial literacy. Mahasiswa bisa memulainya ketika memiliki pendapatan yang diperoleh dari pemberian orangtua berupa allowance (uang saku) ataupun yang telah memiliki penghasilan pribadi. Potrich, Vieira, \& Kirch (2014) menyatakan bahwa dengan memiliki financial literacy yang baik diharapkan mahasiswa akan terhindar dari masalah-masalah keuangan yang dapat terjadi.

Penelitian yang dilakukan oleh Potrich, Vieira, \& Kirch (2014) yang meneliti pengaruh sosial ekonomi dan demografi terhadap financial literacy di Brazil, menggunakan variabel jenis kelamin, status pernikahan, jumlah anak, 
pekerjaan, usia, tingkat pendidikan, dan penghasilan pribadi sebagai indikator yang mempengaruhi financial literacy. Pada penelitiannya, ditemukan bahwa variabel jenis kelamin, jumlah tanggungan, tingkat pendidikan individu, serta penghasilan individu memiliki pengaruh yang signifikan terhadap financial literacy, sedangkan variabel status pernikahan, pekerjaan, dan usia tidak mempengaruhi tingkat financial literacy mahasiswa.

Penelitian yang dilakukan oleh Yashica \& Kartini (2017), yang menggunakan variabel jenis kelamin, usia, tahun angkatan dan IPK mahasiswanya untuk menganalisis tingkat financial literacy mahasiswa, menunjukkan bahwa terdapat perbedaan tingkat financial literacy berdasarkan jenis kelamin, usia, tahun angkatan, dan IPK. Hal ini tentu bertolak belakang dengan hasil penelitian Potrich, Vieira, \& Kirch (2014) berdasarkan variabel usia. Perbedaan ini tentu perlu lebih diperdalam dengan membandingkan dengan hasil penelitian-penelitian yang lebih terdahulu lagi, sehingga dapat ditemukan sebuah celah penelitian mengenai financial literacy.

Perbedaan temuan dari beberapa penelitian terdahulu yang telah meniliti faktor-faktor yang mempengaruhi financial literacy, khususnya variabel sosial ekonomi, demografi dan IPK, sehingga menjadi research gap, seperti pada penelitian Research (2003), Calamato (2010), Krishna, Rofaida, \& Sari (2010), Monticone (2010), Nidar \& Bestari (2012), Luksander \& Beres (2014), dan Potrich, Vieira, \& Kirch (2014) yang meneliti indikator sosial ekonomi (masa bekerja dan tingkat pendapatan), begitu juga dengan penelitian terhadap faktor demografinya (jenis kelamin, status pernikahan) yang dilakukan oleh Researh 
(2008), Calamato (2010), Krishna, Rofaida, \& Sari (2010), Brown \& Graf (2013), Nidar \& Bestari (2012), Luksander \& Beres (2014), Potrich, Vieira, \& Kirch (2014), Rita \& Pesudo (2014), dan Yashica \& Kartini (2017). Pada variabel IPK juga ditemukan berbeda pada penelitian yang dilakukan oleh cude dkk (2006), Krishna, Rofaida, \& Sari (2010), Nidar \& Bestari (2012), Rita \& pesudo (2014), dan Yashica \& Kartini.

Penelitian ini bertujuan untuk menjawab celah penelitian yang terdapat pada penelitian - penelitian terdahulu tersebut, baik dari faktor sosial ekonomi, demografi dan IPK. Penelitian ini dilakukan di Provinsi Bali karena masih jarangnya tema penelitian mengenai financial literacy yang ditemui di Provinsi Bali. Penelitian ini berangkat mulai dari fenomena yang sedang terjadi dan menyandingkannya dengan teori para ahli serta penelitian empiris penelitian terdahulu, sehingga didapat hipotesis sementara yang selanjutnya diuji menggunakan alat analisis PLS (Partial Least Square). Hal ini diharapkan dapat menjawab celah penelitian terdahulu.

Pada hasil observasi, masih ditemukan mahasiswa MM Unud yang belum memahami produk-produk keuangan yang ditawarkan oleh lembaga keuangan, yang menyebabkan kurangnya pemanfaatan terhadap produk-produk keuangan, seperti produk tabungan, investasi dan asuransi. Hal ini membuat penelitian ini menarik untuk dilakukan terhadap mahasiswa Program Studi Magister Manajemen di Universitas Udayana (Unud), yang dipercaya memiliki wawasan finansial yang lebih luas bila dibandingkan dengan mahasiswa program studi lainnya atau bahkan pada level dibawah Program Magister. Mahasiswa Program 
Studi Magister juga lebih memiliki beragam karakteristik bila dilihat dari aspek yang akan diteliti pada penelitian ini, seperti: tingkat pendapatan, masa bekerja, jenis kelamin, status pernikahan dan IPK.

Adapun rumusan masalah dalam penelitian ini adalah sebagai berikut:

1) Bagaimana pengaruh Sosial Ekonomi terhadap Financial Literacy?

2) Bagaimana pengaruh Jenis Kelamin terhadap Financial Literacy?

3) Bagaimana pengaruh Status Pernikahan terhadap Financial Literacy?

4) Bagaimana pengaruh IPK terhadap Financial Literacy?

\section{METODE PENELITIAN}

\section{Jenis dan Sumber Data}

Penelitian ini menggunakan data primer, dengan menggunakan instrumen penelitian berupa kuesioner. Model kuesioner penelitian ini akan mereplikasi model kuesioner pad apenelitian Potrich, Vieira, \& Kirch (2014) di Brazil.

Data yang dimaksud berupa pernyataan dan jawaban pertanyaan dari responden melalui penyebaran kuesioner yang berkaitan dengan variabel penelitian, yaitu faktor sosial ekonomi, demografi, IPK dan financial literacy, beserta indikator financial attitude, financial behaviour, dan financial knowledge.

\section{Variabel Penelitian}

Penelitian ini menggunakan variabel independen dan variabel dependen. Variabel independen pada penelitian ini adalah sosial ekonomi $\left(\mathrm{X}_{1}\right)$, jenis kelamin 
$\left(\mathrm{X}_{2}\right)$, status pernikahan $\left(\mathrm{X}_{3}\right)$, dan IPK $\left(\mathrm{X}_{4}\right)$. Variabel dependen pada penelitian ini adalah financial literacy (Y).

\section{Populasi dan Sampel}

Populasi pada penelitian ini adalah seluruh mahasiswa yang sedang menempuh Program Studi Magister Manajemen Universitas Udayana dan telah memiliki penghasilan.

\section{Metode Penentuan Sampel}

Teknik pengambilan sampel dalam penelitian ini menggunakan teknik sampel insidential. Pada penelitian ini responden akan didatangi langsung ke lokasi perkuliahan dan memberikan kuesioner hanya kepada mahasiswa program studi Magister Manajemen Unud dan telah memiliki penghasilan setiap bulannya / bekerja.

Pada penelitian ini akan mengacu pada teori penentuan jumlah sampel Sekaran \& Bougie (2009) yang mengatakan bahwa ukuran sampel sebaiknya 10x atau lebih dari jumlah variabel dalam penelitian. Berdasarkan hal tersebut, terdapat 6 variabel, yang terdiri dari 2 (dua) indikator sosial ekonomi (tingkat pendapatan dan masa bekerja), 2 (dua) variabel independen dari faktor demografi (jenis kelamin dan status pernikahan), 1 (satu) variabel independen IPK serta 1 (satu) variabel dependen, maka dengan mengacu pada teori penentuan sampel Sekaran \& Bougie (2009), maka jumlah sampel pada penelitian ini adalah 6 x 10 $=60$ sampel. 


\section{Metode Analisis Data}

Instrumen penelitian yang digunakan diuji terlebih dahulu untuk mengetahui apakah instrumen tersebut reliabel. Pengujian ini akan menggunakan alat bantu SPSS 17, untuk mengukur nilai cronbach alpha. Instrumen peneletian dikatakan reliabel apabila nilai cronbach alpha lebih besar dari 0,6.

Analisis selanjutnya adalah analisis deskripsi, yang bertujuan untuk menganalisis karakteristik responden penelitian, sehingga didapat gambaran persepsi responden terhadap indikator-indikator dalam membentuk atau merefleksikan variabel yang digunakan pada penelitian ini.

Analisis terakhir adalah analisis inferensial yang digunakan untuk menguji hipotesis yang diformulasikan dalam penelitian. Data dianalisis dengan menggunakan Structural Equation Modelling (SEM) dengan pendekatan Partial Least Square (PLS) dengan proses perhitungan dibantu program aplikasi software SmartsPLS 3.0. Pengujian dilakukan terlebih dahulu terhadap evaluasi outer model, yang dilanjutkan pada evaluasi innermodeldan ditutup dengan analisis jalur untuk menguji hipotesis penelitian ini.

\section{HASIL ANALISIS}

\section{Deskripsi Penelitian Berdasarkan Demografi}

Variabel sosial ekonomi dalam penelitian ini memiliki 2 (dua) indikator utama, yaitu indikator tingkat pendapatan mahasiswa dan masa bekerja mahasiswa. Hasil analisis deskriptif mengenai variabel Sosial ekonomi ditunjukkan dalam Tabel 1. 
Berdasarkan Tabel 1, responden penelitian sudah memiliki pekerjaan yang cukup baik dan sanggup secara ekonomi, selain itu, responden telah memiliki pengalaman kerja yang cukup dalam hidupnya dan dengan memiliki pengalaman yang cukup, diharapkan responden telah memiliki pengetahuan mengenai ekonomi dan finansial yang lebih baik.

Tabel 1.

Deskripsi berdasarkan Sosial Ekonomi

\begin{tabular}{|c|c|c|c|c|c|}
\hline No. & Variabel & Indikator & Klasifikasi & $\begin{array}{c}\text { Jumlah } \\
\text { (responden) }\end{array}$ & Persentase \\
\hline \multirow{4}{*}{1} & \multirow{4}{*}{$\begin{array}{c}\text { Sosial } \\
\text { Ekonomi }\end{array}$} & \multirow{4}{*}{$\begin{array}{c}\text { Tingkat } \\
\text { pendapatan }\end{array}$} & $<3.500 .000$ & 4 & $7 \%$ \\
\hline & & & $3.500 .001 \mathrm{~s} / \mathrm{d} 5.000 .000$ & 18 & $30 \%$ \\
\hline & & & $5.000 .001 \mathrm{~s} / \mathrm{d} 10.000 .000$ & 36 & $60 \%$ \\
\hline & & & $>10.000 .000$ & 2 & $3 \%$ \\
\hline \multirow{6}{*}{2} & \multirow{6}{*}{$\begin{array}{c}\text { Sosial } \\
\text { Ekonomi }\end{array}$} & \multirow{5}{*}{ Masa Bekerja } & & 60 & $100 \%$ \\
\hline & & & $<1$ tahun & 4 & $7 \%$ \\
\hline & & & $1 \mathrm{~s} / \mathrm{d} 3$ tahun & 13 & $22 \%$ \\
\hline & & & $3 \mathrm{~s} / \mathrm{d} 5$ tahun & 12 & $20 \%$ \\
\hline & & & $>5$ tahun & 31 & $52 \%$ \\
\hline & & Jumlah & & 60 & $100 \%$ \\
\hline
\end{tabular}

Sumber : Olahan data responden penelitian (2017)

\section{Deskripsi Variabel Penelitian Berdasarkan Demografi}

Variabel demografi dalam penelitian ini memiliki 2 (dua) indikator utama, yaitu indikator jenis kelamin dan status pernikahan. Variabel terakhir pada penelitian ini adalah IPK. Hasil analisis deskriptif berdasarkan variabel Demografi ditunjukkan dalam Tabel 2.Berdasarkan Tabel 2 teresbut, mengindikasikan bahwa mayoritas mahasiswa yang menjadi responden penelitian adalah perempuan. 
Hal ini juga menunjukkan bahwa responden penelitianmemiliki rata-rata usia yang seragam di bawah 30 tahun. Berdasarkan IPK-nya, responden penelitian ini memiliki tingkat kecerdasan yang cukup tinggi, dan diharapkan sudahpaham mengenai pengetahuan keuangan.

Tabel 2.

Deskripsi berdasarkan Demografi

\begin{tabular}{|c|c|c|c|c|c|}
\hline No. & Variabel & Indikator & Klasifikasi & $\begin{array}{c}\text { Jumlah } \\
\text { (responden) }\end{array}$ & Persentase \\
\hline \multirow{3}{*}{1} & \multirow{3}{*}{$\begin{array}{c}\text { Sosio- } \\
\text { demografi }\end{array}$} & \multirow{2}{*}{$\begin{array}{c}\text { Jenis } \\
\text { Kelamin }\end{array}$} & Laki-Laki & 17 & $28 \%$ \\
\hline & & & Perempuan & 43 & $72 \%$ \\
\hline & & Jumlah & & 60 & $100 \%$ \\
\hline \multirow{2}{*}{2} & \multirow{2}{*}{$\begin{array}{c}\text { Sosio- } \\
\text { demografi }\end{array}$} & \multirow{2}{*}{$\begin{array}{c}\text { Status } \\
\text { Pernikahan }\end{array}$} & $\begin{array}{l}\text { Sudah } \\
\text { Menikah }\end{array}$ & 18 & $30 \%$ \\
\hline & & & $\begin{array}{l}\text { Belum } \\
\text { Menikah }\end{array}$ & 42 & $70 \%$ \\
\hline \multirow{6}{*}{3} & & Jumlah & & 60 & $100 \%$ \\
\hline & & & $<3.00$ & 4 & $7 \%$ \\
\hline & \multirow{3}{*}{\multicolumn{2}{|c|}{ IPK }} & $3.01 \mathrm{~s} / \mathrm{d} 3.35$ & 13 & $22 \%$ \\
\hline & & & $3.36 \mathrm{~s} / \mathrm{d} 3.65$ & 18 & $30 \%$ \\
\hline & & & $>3.65$ & 25 & $42 \%$ \\
\hline & & Jumlah & & 60 & $100 \%$ \\
\hline
\end{tabular}

Sumber : Olahan data responden penelitian (2017)

\section{Deskripsi Variabel Penelitian Berdasarkan Financial Literacy}

Variabel financial literacy dalam penelitian ini terdiri dari 3 (tiga) indikator utama yaitu financial attitude, financial behaviour, dan financial knowledge. Financial attitude terdiri dari 10 (sepuluh) pernyataan, financial behaviour terdiri dari 27 (dua puluh tujuh) pernyataan dan financial knowledge terdiri dari 10 pertanyaan pilihan berganda. Hasil analisis deskriptif mengenai variabel financial literacy ditunjukkan dalam Tabel 4. Penentuan skor masing-masing indikator 
I Gusti Ngurah Narindra Mandala, dan Luh Putu Wiagustini. Pengaruh Variabel Sosial ...

pada Tabel 4 dihitung berdasarkan skor yang telah ditetapkan oleh OJK yang dapat dilihat pada Tabel 3 sebagai berikut:

Tabel 3.

Penentuan Skor Literasi Keuangan

\begin{tabular}{ccc}
\hline Skor & Skala Skor Literasi Keuangan & Keterangan \\
\hline 1 & $0 \mathrm{~s} / \mathrm{d} 2,06 \%$ & Not Literate \\
2 & $2,07 \% \mathrm{~s} / \mathrm{d} 21,84 \%$ & Less Literate \\
3 & $21,85 \% \mathrm{~s} / \mathrm{d} 75,68 \%$ & Sufficient Literate \\
4 & $>75,68 \%$ & Well Literate \\
\hline (Sumber: OJK, 2017)
\end{tabular}

Berdasarkan Tabel 3, maka mahasiswa yang memiliki skor 4 maka akan dikategorikan memiliki tingkat literasi keuangan "well literate", level selanjutnya adalah "sufficient literate", "less literate" dan "not literate".

Tabel 4.

Analisis Deskripsi berdasarkan Financial Literacy

\begin{tabular}{|c|c|c|c|c|c|c|c|c|}
\hline \multirow[t]{2}{*}{ Dimensi } & \multicolumn{4}{|c|}{$\begin{array}{l}\text { Rekap Skor Literasi } \\
\text { Keuangan Resp. }\end{array}$} & \multirow[t]{2}{*}{ Jumlah } & \multirow{2}{*}{$\begin{array}{l}\text { Rata- } \\
\text { rata }\end{array}$} & \multirow{2}{*}{$\begin{array}{l}\text { Round } \\
\text { up }\end{array}$} & \multirow[t]{2}{*}{ Keterangan } \\
\hline & 1 & 2 & 3 & 4 & & & & \\
\hline $\begin{array}{l}\text { Financial } \\
\text { Attitude }\end{array}$ & 0 & 4 & 24 & 32 & 60 & 2.97 & 3 & Sufficient Literate \\
\hline $\begin{array}{l}\text { Financial } \\
\text { Behaviour }\end{array}$ & 0 & 6 & 17 & 37 & 60 & 3.01 & 3 & Sufficient Literate \\
\hline $\begin{array}{l}\text { Financial } \\
\text { Knowledge }\end{array}$ & 0 & 1 & 22 & 37 & 60 & 3.09 & 3 & Sufficient Literate \\
\hline \multicolumn{6}{|c|}{ Rata-rata konstruk financial literacy } & 3.02 & & Sufficient Literate \\
\hline
\end{tabular}

Sumber : Olahan data responden penelitian (2017)

Berdasarkan Tabel 4, baik pada indikator financial attitude, financial behaviour dan financialknowledge, responden memiliki rata-rata skor di 3,00 yang dapat diartikan bahwa responden pada penelitian ini memiliki tingkat literasi keuangan berdasarkan sikap, tingkah laku dan pengetahuannya dengan kategori 
sufficient literate yakni memiliki pengetahuan dan keyakinan tentang lembaga jasa keuangan serta produk dan jasa keuangan, termasuk fitur, manfaat dan risiko, hak dan kewajiban terkait produk dan jasa keuangan (OJK, 2017).

\section{Analisis Inferensial}

Pada penelitian inianalisis PLS (Partial Least Square) menggunakan alat bantu analisis program SmartPLS 3.2.6. Terdapat dua evaluasi model mendasar dalam pengujian ini yaitu outer model dan inner model. Pengujian inner model dalam PLS dilakukan melalui resampling bootstrap dengan menggunakan 500 sub-sampel yang dilakukan secara random oleh program SmartPLS.

\section{Evaluasi Outer Model}

\section{Convergent validity}

Suatu indikator dinyatakan valid jika mempunyai loading factor di atas 0,5 terhadap variabel yang dituju. Output SmartPLS 3.2.6 untuk loading factor memberikan hasil sebagai berikut:

Tabel 5.

Hasil Outer Loading

\begin{tabular}{|c|c|c|c|c|c|}
\hline & $\begin{array}{c}\text { Financial } \\
\text { Literacy }\end{array}$ & IPK & $\begin{array}{c}\text { Jenis } \\
\text { Kelamin }\end{array}$ & $\begin{array}{c}\text { S. } \\
\text { Pernikahan }\end{array}$ & $\begin{array}{c}\text { Sosial } \\
\text { Ekonomi }\end{array}$ \\
\hline Fin. Attitude & 0,920 & & & & \\
\hline Fin. Behaviour & 0,929 & & & & \\
\hline Fin. Knowledge & 0,888 & & & & \\
\hline IPK & & 1,000 & & & \\
\hline Jenis Kelamin & & & 1,000 & & \\
\hline Masa Bekerja & & & & & 0,948 \\
\hline S. Pernikahan & & & & 1,000 & \\
\hline T. Pendapatan & & & & & 0,930 \\
\hline
\end{tabular}


I Gusti Ngurah Narindra Mandala, dan Luh Putu Wiagustini. Pengaruh Variabel Sosial ...

Pengujian validitas untuk indikator formatif dan reflektif menggunakan korelasi antara skor indikator dengan skor variabel latennya. Indikator reflektif cocok digunakan untuk mengukur persepsi sehingga penelitian ini menggunakan indikator reflektif untuk variabel financial literacy, sedangkan variabel masa bekerja menggunakan indikator formatif untuk mengukurnya. Berdasarkan Tabel 5 menunjukkan bahwa nilai loading factor untuk masing-masing skor indikator terhadap skor variabel latennya telah memenuhi syarat yaitu disarankan lebih besar 0,5. Nilai paling kecil adalah sebesar 0,888 untuk indikator financial knowledge. Nilai 1,000 pada beberapa indikator, mengindikasikan bahwa indikator tersebut adalah dummy, karena secara riil, variabel latennya tidak memiliki indikator / single variable. Berdasakran nilai loading factor tersebut, maka indikator yang dipergunakan pada penelitian ini adalah valid atau telah memenuhi convergent validity. Berikut adalah diagram loading factor masingmasing indikator dalam model penelitian:

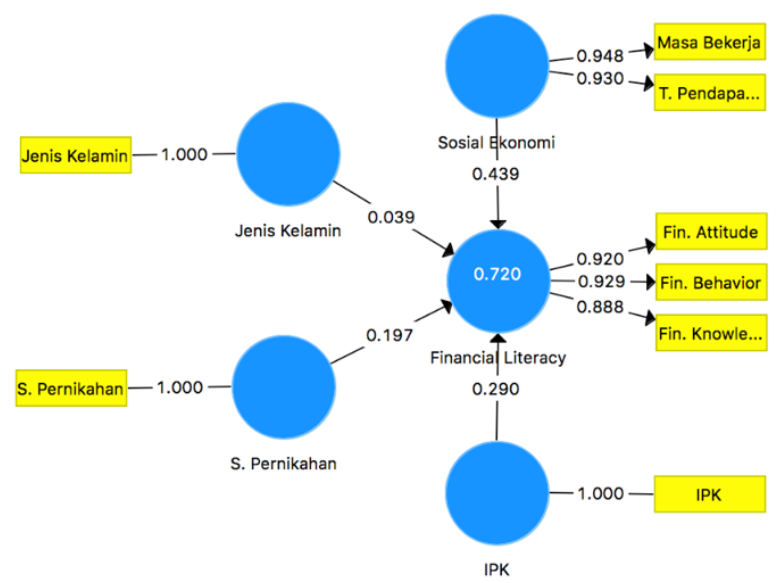

Gambar 1.

Diagaram Nilai Loading Factor 


\section{Discriminant validity}

Salah satu cara untuk melihat discriminant validity suatu variabel adalah dengan melihat loading factor tertinggi kepada variabel yang dituju bila dibandingkan dengan loading factor kepada variabel lain pada output cross loading SmartPLS 3.0 sebagai berikut:

Tabel 6.

Hasil Cross Loading

\begin{tabular}{lccccc}
\hline & $\begin{array}{c}\text { Financial } \\
\text { Literacy }\end{array}$ & $\begin{array}{c}\text { Sosial } \\
\text { Ekonomi }\end{array}$ & $\begin{array}{c}\text { Jenis } \\
\text { Kelamin }\end{array}$ & $\begin{array}{c}\text { S. } \\
\text { Pernikahan }\end{array}$ & IPK \\
\hline Fin. Attitude & 0,920 & 0,700 & 0,295 & 0,553 & 0,773 \\
Fin. Behaviour & 0,929 & 0,845 & 0,319 & 0,667 & 0,734 \\
Fin. Knowledge & 0,888 & 0,639 & 0,368 & 0,612 & 0,559 \\
T. Pendapatan & 0,698 & 0,930 & 0,178 & 0,592 & 0,627 \\
Masa Bekerja & 0,808 & 0,948 & 0,369 & 0,627 & 0,828 \\
Jenis Kelamin & 0,356 & 0,299 & 1,000 & 0,476 & 0,318 \\
S. Pernikahan & 0,671 & 0,650 & 0,476 & 1,000 & 0,584 \\
IPK & 0,761 & 0,782 & 0,318 & 0,584 & 1,000 \\
\hline Sumber : Output SmartPLS $(2017)$ & & & &
\end{tabular}

Berdasarkan Tabel 6, menunjukkan bahwa loading factor untuk indikator financial attitude, financial behaviour dan financial knowledge mempunyai loading factor terhadap variabel laten financial literacy lebih tinggi dibandingkan terhadap variabel laten yang lainnya. Pada hal ini, nilai loading factor indikator financial attitude terhadap variabel financial literacy adalah 0,920. Nilai ini lebih besar bila dibandingkan loading factor -nya terhadap variabel sosial ekonomi $(0,700)$ jenis kelamin $(0,295)$, status pernikahan $(0,553)$ dan IPK $(0,773)$ begitu juga dengan indikator financial behaviour dan financial knowledge terhadap 
variabel financial literacy (berturut-turut 0,929 dan 0,888) lebih besar bila dibandingkan terhadap variabel laten lainnya.

Hal serupa juga terjadi pada indikator tingkat pendapatan dan masa bekerja yang memiliki nilai loading factor terhadap variabel laten sosial ekonomi, berturut-turut 0,930 dan 0,948 , lebih besar bila dibandingkan dengan nilai loading factor terhadap variabel laten lainnya.

Pada indikator variabel demografi, dikarenakan hanya memiliki indikator dummy, maka baik variabel jenis kelamin, status pernikahan dan IPK memiliki nilai loading factor 1,00 dan lebih besar bila dibandingkan terhadap variabel laten lainnya.

\section{Uji reliabilitas}

Uji reliabilitas dilakukan dengan melihat nilai composite reliability dari blok indikator yang mengukur variabel. Hasil composite reliability akan menunjukkan nilai yang memuaskan jika di atas 0,7 . Berikut adalah nilai composite reliability pada output SmartPLS 3.2.6:

Tabel 7.

\begin{tabular}{|c|c|}
\hline \multicolumn{2}{|c|}{ Hasil Composite Reliability } \\
\hline & $\begin{array}{l}\text { Composite } \\
\text { Reliability }\end{array}$ \\
\hline Financial Literacy & 0.937 \\
\hline Sosial Ekonomi & 0.937 \\
\hline Jenis Kelamin & 1.000 \\
\hline S. Pernikahan & 1.000 \\
\hline IPK & 1.000 \\
\hline
\end{tabular}


Berdasarkan Tabel 7, hasil analisis menunjukkan bahwa nilai composite reliability untuk variabel financial literacy (Y) adalah 0,937 ; variabel sosial ekonomi $\left(\mathrm{X}_{1}\right)$ adalah 0,937 ; sedangkan variabel jenis kelamin $\left(\mathrm{X}_{2}\right)$, variabel status pernikahan $\left(\mathrm{X}_{3}\right)$ dan variabel IPK $\left(\mathrm{X}_{4}\right)$ adalah 1,000 . Semua variabel memiliki nilai composite reliability di atas 0,7 atau yang disarankan.

\section{Evaluasi Model Struktural atau Inner Model}

Pada model struktural penelitian ini hanya terdapat sebuah variabel dependen, yaitu financial literacy $(\mathrm{Y})$. Koefiensi determinasi $\left(\mathrm{R}^{2}\right)$ dari variabel tersebut adalah sebagai berikut:

Tabel 8.

Nilai R-square

\begin{tabular}{lc}
\hline & R Square \\
\hline Financial Literacy & 0,720 \\
\hline Sumber : Output SmartPLS &
\end{tabular}

Berdasarkan Tabel 8, nilai R-square untuk variabel financial literacy adalah 0,720 yang berarti variabel sosial ekonomi, demografi dan IPK mampu menjelaskan varians financial literacy sebesar 72,0\%, sedangkan sebesar 28,0\% dipengaruh oleh variabel lainnya yang tidak diuji pada penelitian ini.

Selanjutnya, untuk mengukur seberapa baik nilai observasi dihasilkan oleh model dan juga parameternya, maka perlu menghitung $Q$-square sebagai berikut:

$$
\begin{aligned}
\mathrm{Q}^{2} & =1-\left(1-\mathrm{R}^{2}\right) \quad \ldots \ldots \ldots \ldots \ldots \ldots \ldots \ldots . . .(\text { Pers. 1.) } \\
& =1-(1-0,720) \\
& =0,720
\end{aligned}
$$


Besaran Q-square memiliki nilai dengan rentang $0<\mathrm{Q}^{2}<1$, dimana semakin mendekati satu berarti model semakin baik. Hasil perhitungan tersebut didapat nilai $\mathrm{Q}^{2}$ adalah sebesar 0,720 , sehingga dapat disimpulkan bahwa model memiliki predictive relevance yang sangat baik $\left(\mathrm{Q}^{2}=0,720>0\right)$.

\section{Pengujian Hipotesis}

Penelitian ini menggunakan pendekatananalisis Partial Least Square(PLS) untuk melakukan uji dan analisis terhadap hipotesis penelitian yang telah dikemukakan sebelumnya. Hasil analisis model empiris penelitian dengan menggunakan alat analisis Partial Least Square (PLS).

Pada tahapan pengujian pengaruh langsung, akan digunakan hasil dari SmartPLS 3.0 yang memperlihatkan Path Coefficients hubungan antar variabel, dan membandingkan t-hitung dengan t-tabel $(2,00247)$. Berikut adalah hasil analisis tersebut:

Tabel 9.

Path Coefficients

\begin{tabular}{lccc}
\hline & $\begin{array}{c}\text { Original } \\
\text { Sample } \\
\text { Estimate }\end{array}$ & t-hitung & P Values \\
\hline Sosial Ekonomi -> Financial Literacy & 0.439 & 2.696 & 0.007 \\
Jenis Kelamin -> Financial Literacy & 0.039 & 0.393 & 0.694 \\
S. Pernikahan ->Financial Literacy & 0.197 & 1.234 & 0.218 \\
IPK ->Financial Literacy & 0.290 & 2.169 & 0.031 \\
\hline Sumber : Output SmartPLS Bootstraping (2017) & & &
\end{tabular}

Berdasarkan Tabel 9, hubungan antara $\mathrm{X}_{1}$ (Sosial Ekonomi) dengan $\mathrm{Y}$ (Financial Literacy) adalah signifkan dengan t-hitung sebesar 2,696 (lebih besar dari t-tabel) dan nilai dari original sample estimate adalah positif yaitu 0,439 , 
maka arah hubungan antara $\mathrm{X}_{1}$ (Sosial Ekonomi) dengan Y (Financial Literacy) adalah positif.

Hubungan antara $\mathrm{X}_{2}$ (Jenis Kelamin) dengan $\mathrm{Y}$ (Financial Literacy) adalah tidak signifkan dengan t-hitung sebesar 0,393 (lebih kecil dari t-tabel) dan nilai dari original sample estimate adalah positif yaitu 0,039 , maka arah hubungan antara $\mathrm{X}_{2}$ (Jenis Kelamin) dengan Y (Financial Literacy) adalah positif.

Hubungan antara $\mathrm{X}_{3}$ (Status Pernikahan) dengan Y (Financial Literacy) adalah tidak signifkan dengan t-hitung sebesar 1,234 (lebih kecil dari t-tabel) dan nilai dari original sample estimate adalah positif yaitu 0,197 , maka arah hubungan antara $\mathrm{X}_{3}$ (Status Pernikahan) dengan Y (Financial Literacy) adalah positif.

Hubungan antara $\mathrm{X}_{4}(\mathrm{IPK})$ dengan $\mathrm{Y}$ (Financial Literacy) adalah signifkan dengan t-hitung sebesar 2,169 (lebih besar dari t-tabel) dan nilai dari original sample estimate adalah positif yaitu 0,290, maka arah hubungan antara $\mathrm{X}_{4}$ (IPK) dengan Y (Financial Literacy) adalah positif.

\section{PEMBAHASAN}

\section{Pengaruh Sosial Ekonomi Terhadap Financial Literacy}

Hasil analisis menunjukkan bahwa sosial ekonomi mahasiswa MM Unud berpengaruh positif dan signifikan terhadap financial literacy. Hal ini memiliki makna bahwa semakin baik sosial ekonomi, yang diukur dari masa bekerja dan tingkat pendapatan mahasiswa Magister Manajemen Unud, maka semakin tinggi financial literacy-nya, yang diukur dengan indikator financial attitude, financial behaviour dan financial knowledge. Berdasarkan hal tersebut, dapat diketahui 
bahwa indikator masa bekerja dapat memprediksi lebih baik pengaruh sosial ekonomi terhadap financial litercy dibandingkan dengan indikator tingkat pendapatan. Hal ini dikarenakan nilai loading factor indikator masa bekerja $(0,948)$ lebih besar bila dibandingkan dengan indikator tingkat pendapatan (0,930), namun dikarenakan perbedaan yang tidak terlalu signifikan ini, kedua indikator ini sama-sama memiliki korelasi yang kuat dalam memprediksi pengaruh sosial ekonomi terhadap financial literacy. Semakin lama masa bekerja mahasiswa Magister Manajemen Unud maka semakin baik tingkat literasi keuangannya dan semakin tinggi pendapatannya maka semakin baik tingkat literasi keuangannya.

Lamanya seseorang bekerja dapat menambahkan pengamalan orang tersebut baik dari segi keahlian pada bidang pekerjaannya, maupun dari informasi yang didapatkan dari lingkungan kerjanya. Apabila orang tersebut bekerja di suatu perusahaan keuangan dengan pengalaman yang lama, tentu diharapkan orang tersebut memiliki pengetahuan ekonomi dan finansial yang lebih baik. Bekerja pada perusahaan non-keuangan juga dapat meningkatkan pengetahuan keuangannya, informasi mengenai keuangan dan seputar ekonomi bisa didapatkannya dari rekan kerjanya, dengan mengikuti seminar-seminar keuangan, penawaran produk / jasa dari instansi keuangan, dari surat kabar atau mediamedia online lainnya, dan dari pergaulannya di luar jam kerja, seperti saat bertemu teman lama, relasi kerja, teman di kampus Unud, dan masih banyak lagi. Seseorang yang bekerja tentu mengharapkan imbalan berupa gaji yang biasanya didapatkannya tiap bulan sekali. Gaji yang diterimanya ini selanjutnya akan 
dikelola untuk memenuhi kebutuhan hidupnya selama 1 bulan, atau bagi yang memiliki tingkat literasi keuangan yang lebih baik cenderung akan merencanakan kebutuhan masa depannya dengan mulai menabung dan bahkan membeli produk asuransi jiwa dan kesehatan. Semakin besar gaji yang diterimanya, maka semakin besar kesempatannya untuk merencanakan keuangannya untuk masa depannya, namun apabial seseorang tidak dapat mengontrol godaan keinginan jangka pendeknya, maka bisa saja uang tersebut habis tanpa sisa.

Berdasarkan uraian tersebut, maka Hipotesis 1, yang berbunyi faktor sosial ekonomi berpengaruh secara positif dan signifikan terhadap financial literacy mahasiswa MM Unud, diterima dan hasil ini sesuai dengan beberapa penelitian terdahulu mengenai indikator masa bekerja, yaitu: Research (2008), Calamato (2010), dan Krishna, Rofaida, \& Sari (2010) yang menyimpulkan bahwa seseorang yang memiliki masa bekerja lebih lama akan memiliki tingkat financial literacy yang lebih tinggi karena lebih familiar dengan istilah-istilah ekonomi dan finansial, dibandingkan dengan seseorang yang memiliki pengalaman bekerja lebih singkat, dimana orang-orang yang memiliki pengalaman kerja singkat menunjukkan sikap dan tingkah laku yang berbeda. Penelitian ini juga sesuai dengan beberapa penelitian terdahulu mengenai indikator tingkat pendapatan, yaitu: Research (2008), Calamato (2010), Luksander \& Beres (2014), dan Potrich, Vieira dan Kirch (2014) yang menyimpulkan bahwa seseorang yang memiliki tingkat pendapatan lebih tinggi cenderung lebih peka terhadap isu-isu keuangan, karena dapat menyisihkan pendapatannya untuk keperluan finansial di masa depan. 


\section{Pengaruh Jenis Kelamin Terhadap Financial Literacy}

Hasil analisis menunjukkan bahwa jenis kelamin mahasiswa MM Unud tidak berpengaruh secara signifikan namun memiliki pengaruh positif terhadap financial literacy. Hal ini dapat diartikan bahwa baik perempuan maupun laki-laki memiliki tingkat financial literacy yang sama. Hal ini dapat terjadi dikarenakan responden pada penelitian ini adalah mahasiswa yang sedang mengambil Program Studi Magister Manajemen di Unud, yang artinya mahasiswa diharapkan sudah dibekali oleh ilmu pengetahuan, khususnya di bidang ekonomi dan finansial. Penentuan responden penelitian yaitu mahasiswa yang telah memiliki penghasilan juga mempengaruhi hal ini, karena mahasiswa yang telah bekerja tentu diharapkan memiliki pengetahuan mengenai ekonomi dan finansial yang lebih baik dibandingkan yang belum bekerja.

Berdasarkan uraian tersebut, hasil penelitian ini menolak Hipotesis 2, yang berbunyi jenis kelamin berpengaruh secara positif dan signifikan terhadap financial literacy mahasiswa MM Unud, dan hasil analisis ini pun mendukung hasil penelitian oleh Nidar \& Bestari (2012) dan Rita \& Pesudo (2014) yang menemukan bahwa jenis kelamin tidak mempengaruhi secara signifikan terhadap financial literacy. Hasil penelitian ini bertolak belakang dengan temuan penelitian oleh Research (2008), Krishna, Rofaida, \& Sari (2010), Brown \& Graf (2013), Luksander \& Beres (2014), Potrich, Vieira, \& Kirch (2014), dan Yashica \& Kartini (2017) yang menemukan bahwa jenis kelamin berpengaruh secara positif dan signifikan terhadap financial literacy. 


\section{Pengaruh Status Pernikahan Terhadap Financial Literacy}

Hasil analisis menunjukkan bahwa status pernikahan mahasiswa MM Unud tidak berpengaruh secara signifikan namun memiliki pengaruh positif terhadap financial literacy. Hal ini dapat diartikan bahwa baik mahasiswa MM Unud yang telah menikah maupun belum menikah memiliki tingkat literasi keuanganyang sama. Bila ditelaah lebih jauh lagi, hal ini dapat dipengaruhi oleh program studi yang sedang ditempuhnya, yaitu Program Magister Managemen yang memiliki dasar ilmu ekonomi, sehingga perbedaan persepsi mengenai financial literacy dikalangan mahasiswa yang sudah menikah maupun belum menikah tidak begitu signifikan. Menurut Scheresberg (2013), bahwa seseorang dengan usia 30-40 tahun lebih memahami keuangan dibandingkan dengan usia yang lebih muda, maka dengan melihat mayoritas usia mahasiswa yang tersebar mulai dari usia 22 tahun hingga 30 tahun (homogen), maka hal ini mendukung pernyataan tersebut.

Berdasarkan uraian tersebut, hasil penelitian ini menolak Hipotesis 3 yang berbunyi status pernikahan berpengaruh secara positif dan signifikan terhadap financial literacy mahasiswa MM Unud, dan hasil penelitian ini didukung oleh Nidar \& Bestari (2012), Luksander \& Beres (2014), dan Potrich, Vieira, Kirch (2014) yang menemukan bahwa seseorang yang sudah menikah maupun belum menikah tidak memiliki perbedaan terhadap tingkat financial literacy. Hasil ini berlawanan dengan hasil penelitian yang dilakukan oleh Research (2008), Calamato (2010), dan Brown \& Graft (2013) yang menyatakan bahwa seeorang yang belum menikah cenderung memiliki tingkat financial literacy yang lebih rendah. 


\section{Pengaruh IPK Terhadap Financial Literacy}

Hasil analisis menunjukkan bahwa tinggi rendahnya IPK responden berpengaruh secara positif dan signifikan terhadap financial literacy. Hal ini dapat di artikan bahwa semakin tinggi IPK mahasiswa MM Unud, maka semakin tinggi tingkat literasi keuangannya, yang diukur dengan indikator financial attitude, financial behaviour dan financial knowledge.

Hasil tersebut dapat terjadi karena IPK merupakan standard kelulusan untuk setiap universitas. IPK juga merupakan salah satu alat ukur bagi mahasiswa untuk mengukur tingkat intelektual, semakin tinggi IPK mahasiswa yang diperolehnya pada saat masa kuliah, berarti mahasiswa tersebut dapat dikatakan pintar atau memiliki tingkat intelektual yang tinggi. Hal inilah yang mendukung hasil penelitian ini, terlebih program studi yang sedang ditempuhnya adalah program studi Magister Manajemen yang berdasarkan ilmu ekonomi, sehingga mahasiswa yang memiliki IPK tinggi, diharapkan lebih memahami isu-isu mengenai keuangan yang lebih baik dibandingkan dengan yang memiliki IPK lebih rendah.

Berdasarkan uraian tersebut, maka Hipotesis 4: IPK berpengaruh secara positif dan signifikan terhadap financial literacy mahasiswa MM Unud, diterima dan hasil analisis ini mendukung penelitian yang dilakukan oleh Cude dkk (2006), Krishna, Rofaida, \& Sari (2010), dan Yeshica \& Kartini (2017) yang menunjukkan bahwa terdapat perbedaan tingkat literasi keuanganmahasiswa berdasarkan tinggi rendahnya IPK mahasiswanya. Hasil analisis ini bertolak belakang dengan penelitian yang dilakukan oleh Nidar \& Bestari (2012) dan Rita 
\& Pesudo (2014) yang menemukan bahwa IPK tidak memiliki pengaruh yang signifikan terhadap financial literacy.

\section{Financial Literacy}

Berdasarkan hasil analisis, financial literacy yang diukur dengan indikator financial attitude, financial behaviour dan financial knowledge, dipengaruhi secara positif dan signifikan oleh variabel sosial ekonomi dan variabel IPK. Hal ini dapat dilihat dari tingkat korelasi ketiga indicator financial literacy tersebut yang memiliki tingkat korelasi tinggi yaitu di atas 0,8, yaitu: financial attitude (0,920), financial behaviour $(0,929)$, dan financial knowledge $(0,888)$. Hal ini mengindikasikan bahwa ketiga indikator ini sangat penting untuk mengukur financial literacy individu, khususnya mahasiswa Magister Manajemen Unud.

Hasil temuan ini pun mendukung pernyataan OECD (2013) yang menyatakan bahwa financial behaviour merupakan komponen dari financial literacy yang tidak dapat dipisahkan dan memegang peranan kunci untuk mengukur tingkat financial literacy seseorang. Potrich, Vieira, dan Kirch (2014) pun menambahkan bahwa pada penelitian-penelitian sebelumnya, banyak penelitian terdahulu yang menafsirkan financial literacy adalah financial education atau financial knowledge, yang mana financial literacy seharusnya memiliki arti yang lebih luas dari hanya sekedar financial education maupun financial knowledge. Hal ini terbukti dengan nilai korelasi financial knowledge justru memiliki nilai terendah dari ketiga indikator financial literacy. 
Pada akhirnya, penelitian ini tidak sepenuhnya mendukung hasil penelitian oleh Potrich, Vieira, \& Kirch (2014) yang menjadi tujuan dari penelitian ini, yaitu untuk mengetahui apakah hasil penelitian yang dilakukan di Brazil dapat ditemukan sama dengan hasil penelitian di Bali, yang menggunakan instrumen penelitian kuesioner yang sama. Terdapat beberapa hipotesis yang diterima, yaitu $\mathrm{H}_{1}$ : faktor sosial ekonomi berpengaruh secara positif dan signifikan terhadap financial literacy mahasiswa MM Unud; dan $\mathrm{H}_{4}$ : IPK berpengaruh secara positif dan signifikan terhadap financial literacy mahasiswa MM Unud. Adapun hipotesis yang ditolak adalah $\mathrm{H}_{2}$ dan $\mathrm{H}_{3}$ : jenis kelamin dan status pernikahan berpengaruh secara positif dan signifikan terhadap financial literacy mahasiswa MM Unud. Atas dasar tersebut maka hasil penelitian ini berhasil menjawab permasalahan yang ada.

\section{Implikasi Teoritis}

Temuan penelitian ini menunjukkan bahwa sosial ekonomi dan IPK berpengaruh positif dan signifikan terhadap financial literacy, namun berdasarkan demografinya, variabel jenis kelamin dan status pernikahan tidak memiliki pengaruh yang positif dan signifikan. Hasil penelitian ini mampu memberikan kontribusi dalam bentuk empiris mengenai faktor-faktor yang mempengaruhi financial literacy. 


\section{Implikasi Praktis}

Temuan penelitian ini menunjukkan bahwa sosial ekonomi dan IPK berpengaruh positif dan signifikan terhadap financial literacy, namun variabel demografi (jenis kelamin dan status pernikahan) tidak memiliki pengaruh yang signifikan. Hasil analisis ini juga berhasil mengambarkan bahwa mahasiswa MM Unud memiliki tingkat literasi keuangan yang tinggi, atau disebut dengan sufficient literate (yang memiliki tingkat financial literacy mulai dari 21,84\% s/d 75,69\%, yang artinya mahasiswa MM Unud memiliki pengatahuan dan keyakinan tentang lembaga jasa keuangan serta produk dan jasa keuangan, termasuk fitur, manfaat dan risikonya, serta hak dan kewajiban terkait produk dan jasa keuangan tersebut.

Temuan ini akan bermanfaat bagi lembaga keuangan yang hendak menawarkan produk dan jasanya kepada mahasiswa MM Unud, bila dipergunakan dengan baik. Mengetahui informasi ini, lembaga keuangan dapat lebih mudah melakukan penetrasi pada pasarnya (mahasiswa MM Unud), karena lembaga keuangan tidak perlu khawatir jika mahasiswa MM Unud tidak memahami produk dan jasanya, karena dengan tingkat financial literacy yang tinggi maka mahasiswa MM Unud diharapkan lebih mudah untuk mencerna penawaran produk dan jasa dari lembaga keuangan.

\section{Keterbatasan Penelitian}

Hasil penelitian ini memiliki keterbatasan yang dapat dijadikan sebagai celah penelitian selanjutnya, pertama, sampel pada penelitian ini adalah 
mahasiswa Magister Manajemen Universitas Udayana yang sudah bekerja, sehingga penting bagi penelitian di masa mendatang yang ingin memperdalam studi empiris terkait untuk memperluas sampel dan populasi menjadi mahasiswa dengan berbagai latar belakang, mulai dari program Sarjana, Magister hingga Doktoral, atau menambahkan unversitas selain Unud ke dalam penelitiannya, sehingga variasi data yang didapat aka lebih luas dan dapat lebih menggambarkan keadaan sebenarnya. Kedua, penelitian ini hanya meneliti variabel sosial ekonomi, demografi dan IPK untuk memprediksi pengaruhnya terhadap financial literacy, bagi penelitian di masa mendatang dirasa penting untuk menambahkan variabel prediktor lainnya. Apabila penelitian akan dilakukan di luar lingkungan kampus, dirasa penting untuk menambahkan variabel usia, jumlah anak, tingkat pendidikan terakhir, jabatan terakhir, jenis pekerjaan, dan tingakt pendidikan orang tua. Apabila penelitian akan dilakukan di dalam lingkungan kampus atau terhadap mahasiswa, diharapkan mengambil lebih dari 1 fakultas / jurusan dan menambahkan tahun ajaran masuk dan fakultasnya.

\section{SIMPULAN DAN SARAN}

\section{Simpulan}

Berdasarkan hasil analisis, maka dapat disimpulkan bahwa faktor sosial ekonomi berpengaruh secara positif dan signifikan terhadapfinancial literacy. Hal ini memiliki makna bahwa semakin baik sosial ekonomi mahasiswa Magister Manajemen Unud, yang diukur melalui tingkat pendapatan dan masa bekerjanya maka akan meningkatkan financial literacy. Berdasarkan demografinya, variabel 
jenis kelamin dan status pernikahan mahasiswa Magister Manajemen Unud tidak berpengaruh secara signifikan, namun positif terhadap financial literacy. Hal ini memiliki makna bahwa mahasiswa Magister Manajemen Unud yang berjenis kelamin perempuan dan laki-laki serta yang berstatus sudah menikah maupun belum menikah memiliki tingkat financial literacy yang sama. Financial literacy memiliki 3 (tiga) indikator utama, yaitu: financial attitude, financial behaviour, dan financial knowledge. Berdasarkan hasil penelitian, ketiga indikator ini memiliki peranan yang sama kuat dalam mengukur financial literacy, dan yang memiliki peranan lebih kuat adalah financial behaviour dan yang lebih lemah adalah financial knowledge. Hal ini menandakan bahwa tingkat financial literacy lebih ditentukan oleh tingkah laku mahasiswa Program Magister Manajemen Unud.

\section{Saran}

Berdasarkan simpulan penelitian, disarankan bagi peneliti selanjutnya yang akan meneliti financial literacy, diharapkan memperluas sampel menjadi mahasiswa dengan berbagai latar belakang, mulai dari program Sarjana, Magister hingga Doktoral, atau menambahkan unversitas selain Unud ke dalam penelitiannya. Penelitian lebih lanjut juga dapat mengembangkan hal ini dengan meneliti objek selain mahasiswa, seperti masyarakat yang diprediksi memiliki tingkat literasi keuangan yang minim. Penelitian selanjutnya juga diharapkan dapat menambahkan variabel lain selain faktor sosial ekonomi, demografi dan IPK. Menurut hasil penelitian, terdapat 28\% tingkat financial literacy mahasiswa 
dipengaruhi oleh variabel yang tidak diuji pada penelitian ini. Variabel usia, jumlah anak, tingkat pendidikan terakhir, jabatan terakhir, jenis pekerjaan, dan tingakt pendidikan orang tua dirasa perlu untuk digunakan pada penelitian yang akan datang. Apabila penelitian akan dilakukan di dalam lingkungan kampus atau terhadap mahasiswa, diharapkan mengambil lebih dari 1 fakultas / jurusan dan menambahkan tahun ajaran masuk dan fakultasnya.

Bagi praktisi, khususnya lembaga jasa keuangan, agar dapat lebih memperhatikan tingkat financial literacy masyarakat sebelum menetapkannya sebagai target market, karena bila lembaga keuangan tersebut menawarkan produk dan atau jasanya kepada masyarakat yang belum melek keuangan, maka masyarakat akan lebih sulit untuk mencerna maksud dari produk dan jasa yang ditawari tersebut dibandingkan bila ditawarkan kepada masyarakat yang melek keuangan. Hal ini akan berujung pada penolakan oleh masyarakat terhadap produk dan atau jasa tersebut.

Bagi pihak kampus, diharapkan dapat memberikan mata kuliah tambahan mengenai personal finance, sehingga mahasiswa dapat lebih memahami bagaimana cara mengelola keuangan pribadi yang baik dan benar.

Disarankan juga kepada lembaga keuangan dan kampus Universitas Udayana agar dapat terus melanjutkan perannya dalam melakukan inklusi keuangan, sehingga dapat membantu meningkatkan tingkat financial literacy di Indonesia, khususnya di Bali, sehingga masyarakatnya dapat lebih siap dalam menghadapi persaingan MEA. 


\section{REFERENSI}

Brown, M. \& Graf, R. 2013. Financial Literacy and Retirement Planning in Switzerland. Numeracy, Vol. VI: Iss. 2, Article 6.

Calamato, M. P. 2010. Learning Financial Literacy in the Family. Thesis. The Faculty of the Department of Sociology, San José State University. Unpublished.

Cude, B. J., Lawrence F. C., Lyons A. C., Metzger, K., LeJeune, E., Marks, L., \& Machtmes, K. (2006), College Students and Financial Literacy: What They Know and What We Need to Learn. Eastern Family Economics and Resource Management Association, 2006 Conference, pp. 102-109.

Krishna, A., Rofaida, R. \& Sari, M. 2010. Analisis Tingkat Financial Literacy di Kalangan Mahasiswa dan Faktor-Faktor yang Mempengaruhinya (Survey pada Mahasiswa Universitas Pendidikan Indonesia). Proceedings of the 4th International Conference on Teacher Education; Join Conference UPI \& UPSI, Bandung, Indonesia, pp. 8-10.

Luksander, A. \& Beres, D. 2014. Analysis of the Factors that Influence the Financial Literacy of Young People Studying in Higher Education. Public Finance Quarterly 2014/2 (p. 220-241).

Lusardi, A. \& Mitchell, O. S. 2011. Financial Literacy and Retirement Planning in the United States. Working Paper, National Bureau Economic Research, No. 17108

Mien, N. T. N. \& Thao, T. P. (2015). Factors Affecting Personal Financial Management Behaviors: Evidence from Vietnam. Proceedings of the Second Asia-Pacific Conference on Global Business, Economics, Finance and Social Sciences (AP15Vietnam Conference) Danang - Vietnam, 10-12 July.

Monticone, C. (2010). How much does wealth matter in the acquisition of financial literacy? The Journal of Consumer Affairs, Vol. 44, No. 2, pp. 403- 422.

Nidar, S. R. \& Bestari, S. 2012. Personal Financial Literacy Among University Students, Case Study at Padjadjaran University Students, Bandung, Indonesia. World Journal of Social Science, Vol. 2, No. 4, pp. 162-171.

Otoritas Jasa Keuangan (OJK). 2017. Edukasi dan Perlindungan Konsumen, Literasi Keuangan. (online), (http://www.ojk.go.id/id/kanal/edukasi-danperlindungan-konsumen/Pages/Literasi-Keuangan.aspx) 
I Gusti Ngurah Narindra Mandala, dan Luh Putu Wiagustini. Pengaruh Variabel Sosial ...

Organisation for Economic Co-Operation and Development. OECD. (2013). Financial literacy and inclusion: Results of OECD/INFE survey across countries and by gender. Paris: OECD Centre.

Potrich, A. C. G., Vieira, K. M., \& Kirch, G. 2014. Determinants of Financial Literacy: Analysis of the Influence of Socioeconomic and Demographic Variables. R. Cont. Fin. - USP, Sao Paulo, Vol. 26, No. 69, pp. 362-377

Research, R. M. 2008. Survey of Adult Financial Literacy in Australia. (online). (http://www.anz.com/Documents/AU/Aboutanz/AN_5654).

Rita, M. R. \& Pesudo, B. C.A., 2014. Apakah Mahasiswa Sudah Melek Keuangan? Jurnal Dinamika Akuntansi, Keuangan dan Perbankan, Vol. 3, No. 1, pp. 58-65.

Sekaran, U. \& Bougie, R. 2009. Methods for Business - A Skill-Building Approach. 5th Edition. United Kingdom: John Wiley \& Sons Ltd.

Yashica, P. R. \& Kartini. 2017. Analisis Tingkat Financial Literacy dan Financial BehaviourMahasiswa Magister Ekonomi Universitas Islam Indonesia. Journal of Business. Vol. 7, No. 1, pp. 44-56 